\title{
Drug utilization review of tramadol hydrochloride in a regional hospital in South Africa; findings and implications
}

\author{
Akhona Fynn ${ }^{1,2}$, Elvera Helberg ${ }^{1}$, Brian Godman ${ }^{1,3,4,5^{*}}$, Johanna C Meyer ${ }^{1}$ \\ ${ }^{1}$ School of Pharmacy, Sefako Makgatho Health Sciences University, Molotlegi Street, Ga-Rankuwa, \\ Gauteng, South Africa, 0208. Email: tonafynn@yahoo.com; elvera@mweb.co.za; \\ hannelie.meyer@smu.ac.za \\ ${ }^{2}$ Department of Health, KwaZulu-Natal, Pietermaritzburg, South Africa \\ ${ }^{3}$ Strathclyde Institute of Pharmacy and Biomedical Sciences, University of Strathclyde, Glasgow, UK. \\ Email: Brian.Godman@strath.ac.uk \\ ${ }^{4}$ Division of Clinical Pharmacology, Department of Laboratory Medicine, Karolinska Institutet, \\ Karolinska University Hospital Huddinge, Stockholm, Sweden. Email: Brian.Godman@ki.se \\ ${ }^{5}$ Health Economics Centre, University of Liverpool Management School, Liverpool, UK. Email: \\ Brian.Godman@liverpool.ac.uk
}

\begin{abstract}
*Author for correspondence. Division of Clinical Pharmacology, Karolinska Institute, Karolinska University Hospital Huddinge, SE-141 86, Stockholm, Sweden. Email: Brian.Godman@ki.se. Telephone + 46858581068 . Fax + 46859581070 and Strathclyde Institute of Pharmacy and Biomedical Sciences, University of Strathclyde, Glasgow G4 ORE, United Kingdom. Email: brian.godman@strath.ac.uk. Telephone: 0141548 3825. Fax: 01415522562
\end{abstract}

(Accepted for publication Hospital Practice)

\section{ABSTRACT}

Background: Drug utilization reviews (DURs) can be used to promote rational prescribing and ensure compliance with standard treatment guidelines. In recent years, the use of tramadol hydrochloride $(\mathrm{HCl})$ for pain has increased significantly across countries. We sought to determine prescribing patterns and use of tramadol in a Regional Hospital in South Africa to provide future guidance in view of increasing concerns with the prescribing of tramadol. Method: A prospective, quantitative and descriptive study was conducted over two months. Outpatient and inpatient prescriptions and ward requisitions where tramadol $\mathrm{HCl}$ was prescribed or ordered were identified, which included outpatients collecting antiretroviral (ARV) treatment. These were reviewed and evaluated to determine the level of compliance to the Standard Treatment Guidelines and Essential Medicines List (STGs/EML) for South Africa as a measure of the quality of prescribing. Quantities issued to the inpatient wards and expenditure incurred by the pharmacy departments were assessed to determine overall usage and total costs. Results: In total, 415 tramadol $\mathrm{HCl}$ prescriptions were collected over a 2-month period. Compliance was $70.1 \%$ to the STGs/EML. The outpatient pharmacy department had the highest compliance at $76.4 \%$ while the ARV pharmacy compliance was $29.1 \%$. Most prescriptions dispensed at the outpatient pharmacy were from the Surgical Outpatient Department (140; 33.7\%) and the Orthopaedic Outpatient Department (108; $26.0 \%$ ). The outpatient pharmacy had the highest tramadol $\mathrm{HCl}$ consumption and expenditure at $\$ 4,874.13(R 72,054.28)$, while the inpatient pharmacy's expenditure was $\$ 2,526.63$ ( $R 37,351.20)$, and the ARV pharmacy $\$ 590.13(\mathrm{R} 8,722.75)$. The hospital's tramadol $\mathrm{HCl}$ expenditure increased when compared to previous financial years, from $\$ 10,576.04$ (R156,326.00) in 2014-2015 to $\$ 39,584.00$ (R585,088.80) in 2016-2017. Conclusion: This study highlights the need for the implementation of monitoring and evaluation tools to enhance rational prescribing and use of tramadol $\mathrm{HCl}$. These are being implemented and will be evaluated in future projects.

Key words: Tramadol; drug utilization review; guidelines; EML; hospital; South Africa

\section{Introduction}

Tramadol $\mathrm{HCl}$ is a centrally-acting synthetic analgesic compound which acts by inhibiting the reuptake of norepinephrine and serotonin (1), which has a unique dual-action analgesic ability, producing its analgesia by affecting the nociceptive process and the central pain modulation (2-4). Its analgesic properties can be improved by combining it with non-opioid analgesics (2). Initially, tramadol $\mathrm{HCl}$ was perceived to have a lower side-effect profile compared to other opioids and a lower dependency compared with morphine (5-8). As a result, tramadol HCL has been widely used 
in lower- and middle-income countries especially as it is often the only analgesic available for patients with moderate to severe pain, there are concerns with the use of opiods and non-steroidal anti-inflammatory drugs (NSAIDs) in these patients, as well as being relatively inexpensive despite not being on the World Health Organisation's (WHO) essential medicine list (EML) $(6,8,9)$.

However, tramadol $\mathrm{HCl}$ has the ability to induce psychic and physical dependence of the morphine type leading to concerns about the risk of tramadol dependence and abuse potential especially at supratherapeutic doses $(5,8,10)$. In addition, there are concerns including major drug interactions with an appreciable number of medicines as well as the potential for seizures, hallucinations, hypertension and respiratory depression, leading to calls for its prescribing to be carefully monitored (10-17).

Overall, tramadol $\mathrm{HCl}$ is seen as a weak opioid analgesic which has been on the market for many years $(4,18-21)$. Its properties and characteristics have been extensively researched for the treatment of many types of pain, including moderate to moderately severe, acute and chronic pain $(5,8,14,18,19,22,23)$. Recent Cochrane reviews and other systematic analyses have demonstrated its effectiveness in neuropathic pain, chronic low back pain, cancer pain, osteoarthritis and post-operative pain, although there were concerns in patients with rheumatoid arthritis $(2,3,22,24-27)$. There are issues though with the actual level of clinical benefit seen versus other treatments for pain and its adverse effects profile including most commonly nausea, vomiting, dizziness and constipation $(5,8,9,23)$. As a result, patients do discontinue treatment. Research has also shown that tramadol $\mathrm{HCl}$ monotherapy does not always offer adequate pain relief in patients with cancer $(2,21)$.

Despite concerns, the use of tramadol has increased appreciably in recent years with more than 18 million prescriptions now written annually in the US alone $(19,28)$ and, as mentioned, appreciable use in LMICs (6). However in Australia, for instance, the significant increase in the use of opioids during the past two decades resulted in an increase in opioid-related hospitalisation as well as deaths due to accidental poisoning (29). In addition in a number of African and Middle Eastern countries, data have shown an increase in the prevalence of tramadol misuse, contrary to previously reported lower tendencies towards misuse of tramadol as compared to other opioids (8, 20). Due to the increase in tramadol $\mathrm{HCl}$ consumption including the growing abuse of tramadol, the WHO Expert Committee on Drug Dependence has supported a move to critically review the status quo of tramadol $\mathrm{HCl}$ and encouraged countries to introduce further controls if needed to reduce abuse $(20,21)$. However, to date tramadol has not been scheduled by the Expert Committee (6). Clinics have also been established across countries, including South Africa, to address patients' addiction to tramadol (30).

Tramadol $\mathrm{HCl}$ was listed as a Step 2 level in the WHO guidelines for the management of cancerrelated pain; however, this is no longer the case with recommendations generally for opiods as well as non-opiods for persistent or increasing mild to moderate pain (31). Tramadol $\mathrm{HCl}$ has also been listed in the Standard Treatment Guidelines and Essential Medicines List (STG/EML) for Primary Health Care (PHC) in South Africa $(32,33)$. In the latter, tramadol $\mathrm{HCl}$ is indicated for the management of pain in opportunistic infection treatment in adults as well as for chronic non-cancer pain and chronic cancer pain (33).In the STGs/EML for Hospital Level (Adults) in South Africa, tramadol is indicated for peri-operative, post-operative, Zoster, renal calculi and opiate withdrawal (34).

We believe concerns with the potential overuse of tramadol $\mathrm{HCl}$, as well as its side-effect profile and precautions with an appreciable number of medicines, justifies the need for regular drug utilization reviews (DUR) involving a detailed review of the prescriptions of a patient prior to, during, and after dispensing of tramadol, covering all dispensing phases, to ensure positive patient outcomes $(14,18,35,36)$. DURs promote the rational use of medicines and combat wasteful expenditure $(36,37)$. Lack of control measures and implementation thereof to limit the overuse and abuse of tramadol $\mathrm{HCl}$ by both prescribers and patients has made the situation worse. While tramadol $\mathrm{HCl}$ use is not internationally controlled, it is the responsibility of individual countries to exert their own control measures (8). The maximum daily dose of tramadol $\mathrm{HCl}$ in the South African STG EML must not exceed 400mg administered at a dose of 50-100mg 4-6 hourly, which is in line with the recommendation of the WHO's Expert Committee on Drug Dependence (20). This indicates that the dose must be in the range of $100 \mathrm{mg}$ to a maximum of $400 \mathrm{mg}$ daily, with overdosing known for instance to cause acute liver failure (28). DURs are also important where the 
costs of medicines consume an appreciable proportion of the overall health care budget.

Consequently, any activity that seeks to enhance health system efficiency is of benefit especially in countries striving for universal healthcare (38).

In view of these concerns, a DUR of tramadol $\mathrm{HCl}$ was conducted at a regional hospital in South Africa. The aim was to determine the prescribing patterns, use and expenditure on tramadol $\mathrm{HCl}$ in this hospital. The findings are anticipated to provide guidance in this and other settings in South Africa for the future especially among public hospitals. This could include highlighting potential additional control measures to curb abuse and overuse of tramadol $\mathrm{HCl}$ if needed.

\section{Methodology}

\subsection{Study setting and design}

The study was conducted in a regional hospital situated in the KwaZulu-Natal (KZN) province of South Africa. The chosen hospital has 900 beds and caters mainly for the rural community from two of the districts in the province. The hospital serves as a referral hospital to a population of approximately 1.4 million people.

This was a prospective, quantitative and descriptive study. At the time of the study, the hospital was dispensing prescriptions to approximately 1,000 patients per month. With a $95 \%$ confidence interval, $5 \%$ margin of error and $50 \%$ response distribution, a sample size of 415 prescriptions for tramadol $\mathrm{HCl}$ was calculated. These prescriptions were collected over a two-month period (September and October 2016) from patient files in the outpatient (OP) pharmacy and the antiretroviral pharmacy. In addition, ward requisitions and electronic stock control systems for inhospital prescriptions were reviewed to determine inpatient usage.

The principal outcome measure was compliance with either the PHC STGs/EML or the Hospital Level (Adult) STGs/EML $(33,34)$. Consequently, compliance with the diagnosis for tramadol $\mathrm{HCl}$ was determined based on the categories obtained from both these guidelines. The use of the PHC STGs/EML was seen as necessary because some patients might have been initiated on tramadol $\mathrm{HCl}$ by the medical officer at the PHC level and were reporting for a review at the hospital. Consequently, the diagnosis might comply with the PHC STGs/EML but not necessarily with the Hospital Level (Adult) version of the STGs/EML. Furthermore, the PHC STGs/EML clearly states that tramadol $\mathrm{HCl}$ may be used for pain control. It gives a clear description of pain and the medicine treatment steps, and recommends the addition of tramadol $\mathrm{HCl}$ for moderate pain which may not be well controlled with paracetamol and ibuprofen. However, the Hospital Level (Adult) version of the STGs/EML does not recommend tramadol $\mathrm{HCl}$ usage for chronic cancer pain management whilst the PHC STGs/EML recommends tramadol $\mathrm{HCl}$ as a Step 2 weak opioid analgesic. Adherence to guidelines is seen as a better marker for the quality or prescribing than for instance WHO/INRUD criteria $(39,40)$.

\subsection{Data collection}

Data were collected by the pharmacy staff, who received training prior to the data collection, to ensure standardisation of the data collection process. Three data collection tools were used to record the required data as well as a scanner. Approximately 10 prescriptions for tramadol were sampled per day, scanned and filed electronically in a computer for analysis. Records of supplies to the wards were printed from the Cost Man® Electronic Stock Control system and filed after being verified against the ward Schedule 5 requisition. The quantity and cost of tramadol $\mathrm{HCl}$ supplied from the Provincial Pharmaceutical Supply Depot (PPSD) were obtained from the pharmacy store's electronic system, Plankmed®.

\subsection{Data analysis}

Statistical analysis was performed on Statistical Analysis System (SAS) (SAS Institute Inc, Carey NC, USA), Release 9.4, running under Microsoft Windows for a personal computer. The total expenditure was calculated to determine the cost of tramadol $\mathrm{HCl}$ using monthly expenditure reports.

Expenditure was initially collected in South African Rand and subsequently converted to US\$ for comparative purposes. The conversion rate was 1 Rand = US\$0.0676295 (15 Nov 2019; https://www.xe.com/currencyconverter/). 


\subsection{Ethical considerations}

Ethical clearance was obtained from Sefako Makgatho University Research Ethics Committee (SMUREC/H/115/2016:PG). A letter of approval was obtained from the Chief Executive Officer of the institution and from the Provincial Department of Health research unit. Confidentiality of the prescriptions was maintained by using a unique patient identifier and not any personal details.

\section{Results}

\subsection{Sample population}

A total sample of 415 prescriptions for tramadol $\mathrm{HCl}$ were reviewed, comprising 259 females $(62.4 \%)$ and 156 males $(37.6 \%)$. Patients' ages ranged from 18 to 81 years. The majority (360; $86.7 \%$ ) of prescriptions were from the outpatient department (OPD) clinics (Table 1). More than half of the prescriptions were from the Surgical Outpatients Department (SOPD) (140; 33.7\%) and the Orthopaedic Outpatients Department (OOPD) (108; 26.0\%). Fifty-five (13.3\%) of the 415 prescriptions were from the antiretroviral pharmacy (outpatients), catering for HIV positive patients.

Table 1: Prescriptions for tramadol $\mathrm{HCl}$ per hospital department

\begin{tabular}{|l|c|}
\hline Hospital department & $\begin{array}{c}\text { Number }(\mathbf{\%}) \text { of } \\
\text { prescriptions }(\mathbf{n}=\mathbf{4 1 5})\end{array}$ \\
\hline Surgical outpatients' departments (SOPD) & $140(33.7 \%)$ \\
\hline Orthopaedic outpatients' departments (OOPD) & $108(26.0 \%)$ \\
\hline Medical outpatients' departments (MOPD) & $54(13.0 \%)$ \\
\hline Emergency department (ED) & $31(7.5 \%)$ \\
\hline Gynaecology outpatients' departments (GOPD) & $25(6.0 \%)$ \\
\hline Occupational health services (OHS) & $1(0.24 \%)$ \\
\hline No information & $1(0.24 \%)$ \\
\hline Sub-total for outpatient (OP) pharmacy & $\mathbf{3 6 0 ( 8 6 . 7 \% )}$ \\
\hline Antiretroviral pharmacy (outpatients) & $55(13.3 \%)$ \\
\hline TOTAL & $\mathbf{4 1 5 ( 1 0 0 \% )}$ \\
\hline
\end{tabular}

A total of 1,501 items were prescribed on the 415 prescriptions evaluated giving an average of 3.6 medicines per prescription), which means tramadol $\mathrm{HCl}$ was co-prescribed with an additional 1,086 items. Of the 1,501 items reviewed, $415(27.6 \%)$ were for tramadol $\mathrm{HCl}, 517(34.4 \%)$ were adjuvant analgesics and $569(37.9 \%)$ were for other medicines.

\subsection{Compliance with provincial formulary prescriber levels}

All 360 OPD prescriptions were evaluated for compliance with prescriber levels as per the KZN provincial formulary. According to the $\mathrm{KZN}$ provincial formulary, tramadol $\mathrm{HCl}$ is a level $1 \mathrm{~B}$ item, which means it should be initiated by a medical officer (41). In the event where an intern medical officer prescribes tramadol $\mathrm{HCl}$, the prescription must be counter-signed by a senior medical officer or it must have been initiated by a senior medical officer before the prescription can be initiated by an intern medical officer. Non-compliance with the KZN formulary is seen when a prescription is initiated first by anyone other than the senior medical officer, for example a nurse or intern medical officer.

Intern medical officers prescribed $92(25.8 \%)$ of the 360 prescriptions evaluated from the OP pharmacy, and such prescriptions were not compliant in terms of the prescriber levels according to the formulary. Nearly two thirds (62.6\%) were written by medical officers (prescriber Level 2$), 0.3 \%$ by medical registrars (Level 3 ) and $11.2 \%$ by specialist medical officers (Level 4 ). The prescriber level in three $(0.8 \%$ ) of the prescriptions could not be identified because the prescriber's registration number was not recorded on these prescriptions. This could be because when doctors prescribe tramadol $\mathrm{HCl}$ outside of their prescriber level then according to the guidance in the EML/STGs, the pharmacy has to return the prescription for a counter signature. However, in busy facilities this can be overlooked. Both these challenges should be addressed by the pharmacy and therapeutic committee (PTC) in its deliberations. At the antiretroviral pharmacy, all 55 prescriptions were written by Level 2 medical officers, i.e. they do not need to be countersigned.

\subsection{Categories of conditions treated}


The number of conditions for which tramadol HCL was prescribed on the 360 prescriptions evaluated, were considerable. As a result, these were categorised into the different classes of pain obtained from the Hospital Level (Adult) STGs/EML and the PHC STGs/EML $(33,34)$.

A wide range of conditions in which tramadol $\mathrm{HCl}$ can be used to manage pain are listed under chronic non-cancer pain in the PHC STGs/EML as compared to the Hospital Level (Adult) version STGs/EML $(33,34)$. Consequently, to evaluate for compliance of the conditions treated, it was necessary to apply both guidelines in order to determine the appropriate category of pain for each condition. The electronic mobile application, which contains both guidelines, was used for this purpose (32).

The categories of pain used in the compliance evaluation process were zoster, chronic non-cancer pain, acute non-surgical pain, chronic cancer pain, post-operative pain and renal calculi. Applying these categories made it possible to evaluate the prescriptions for diagnosis compliance with the STGs/EML (Table 2). Of the 415 prescriptions evaluated, half of the conditions were categorised as chronic non-cancer pain $(131 ; 31.6 \%)$, followed by acute non-surgical pain $(80 ; 19.3 \%)$. Nearly a third $(124 ; 29.9 \%)$ of the conditions treated could not be classified as any of the pain categories. More detailed information on the conditions treated with tramadol $\mathrm{HCL}$, and whether the treatment was compliant to the STGs/EML or not, is available in Supplement A and Supplement B.

Table 2: Compliance of prescriptions for tramadol $\mathrm{HCL}$ according to pain categories as specified in the STGs/EML

\begin{tabular}{|c|c|c|c|c|c|}
\hline \multirow[b]{2}{*}{ Pain category } & \multicolumn{2}{|c|}{$\begin{array}{l}\text { Outpatient pharmacy } \\
(\mathrm{n}=360)\end{array}$} & \multicolumn{2}{|c|}{$\begin{array}{l}\text { Antiretroviral pharmacy } \\
(n=55)\end{array}$} & \multirow{2}{*}{\begin{tabular}{|l|} 
Total \\
$\begin{array}{l}\text { Number } \\
(\%)\end{array}$ \\
\end{tabular}} \\
\hline & Number (\%) & $\begin{array}{l}\text { Compliant } \\
\text { with } \\
\text { STGs/EML }\end{array}$ & Number (\%) & $\begin{array}{l}\text { Compliant } \\
\text { with } \\
\text { STGs/EML }\end{array}$ & \\
\hline Chronic non-cancer pain & $117(32.5 \%)$ & Yes & $14(25.5 \%)$ & Yes & $131(31.6 \%)$ \\
\hline Acute non-surgical pain & $78(21.7 \%)$ & Yes & $2(3.6 \%)$ & Yes & $80(19.3 \%)$ \\
\hline Post-operation & $53(14.7 \%)$ & Yes & 0 & - & $53(13.8 \%)$ \\
\hline Cancer & $18(5.0 \%)$ & Yes & $1(1.8 \%)$ & Yes & $19(4.6 \%)$ \\
\hline Renal Calculi & $6(1.7 \%)$ & Yes & 0 & - & $6(1.5 \%)$ \\
\hline Zoster & $2(0.6 \%)$ & Yes & 0 & - & $2(0.5 \%)$ \\
\hline Not classifiable & $86(23.9 \%)$ & No & $38(69.1 \%)$ & No & $124(29.9 \%)$ \\
\hline Total & 360 & $\begin{array}{l}274 \text { of } 360 \\
(76.1 \%)\end{array}$ & 55 & $\begin{array}{l}17 \text { of } 55 \\
(30.9 \%)\end{array}$ & 415 \\
\hline
\end{tabular}

NB: STGs/EML: Standard Treatment Guidelines and Essential Medicines List for South Africa; Detailed information available in Supplement A and Supplement B

\subsection{Compliance of adjuvant analgesics with the STGs/EML}

Table 3 shows the different adjuvant analgesics prescribed alongside tramadol $\mathrm{HCl}$ in the 415 prescriptions. Most of these prescriptions contained paracetamol $(345 ; 83.1 \%)$, followed by a nonsteroidal anti-inflammatory drug $(61 ; 14.5 \%)$ and amitriptyline $(56 ; 13,5 \%)$. The least prescribed category was the opioids $(2 ; 0.5 \%)$.

Additional to the analgesics, other medicines prescribed included anti-hypertensives $(81 ; 19.5 \%)$, supplements $(91 ; 21.9 \%)$, antivirals $(70 ; 16.8 \%)$, antibiotics $(52 ; 12.5 \%)$, anti-inflammatories $(29$; $7.0 \%)$, wound dressing treatments $(14 ; 3.4 \%)$, anti-diabetic medicines $(8 ; 1.9 \%)$, anti-convulsants $(8 ; 1.9 \%)$, anti-cancer medicines $(3 ; 0.7 \%)$, and other medicines $(101 ; 24.4 \%)$.

Furthermore, each individual analgesic prescribed for the management of pain was evaluated for compliance with the STGs/EML. A brief summary of the recommendations as stipulated in the guidelines is available as Supplement C. Compliance was considered by determining whether the diagnosis and the dosage were compliant with the guidelines. The dosage interval was not evaluated in our study as pain medication is often recommended to be taken when necessary, especially in patients with acute mild pain. The frequency of medication also depends on the pain intensity, although for chronic pain and cancer pain maintaining the frequency as recommended by 
the guidelines is important. The duration of treatment was not specified in the guidelines; consequently, this was also not taken into account when determining compliance to the STGs/ EML (Table 3).

Paracetamol was the most commonly prescribed analgesic $(345 ; 83.1 \%)$ as it can be prescribed for mild pain but also as an adjuvant to tramadol $\mathrm{HCl}$ for moderate pain management. It is a first line analgesic unless contraindicated. The dosage was 100\% compliant while $94.5 \%$ compliant with respect to conditions treated. Amitriptyline was $96.4 \%$ diagnosis- and $100 \%$ dose compliant, ibuprofen was $95.4 \%$ diagnosis- and $90.2 \%$ dosage compliant, and carbamazepine was found to be $100 \%$ complaint with respect to both diagnosis and dosage. 
Table 3: Therapeutic category of adjuvant analgesics and compliance with STGs/EML ( $n=415)$

\begin{tabular}{|c|c|c|c|c|c|c|c|c|c|}
\hline \multirow[b]{2}{*}{$\begin{array}{l}\text { Pharmacological } \\
\text { class }\end{array}$} & \multirow[b]{2}{*}{$\begin{array}{l}\text { No }(\%) \text { of } \\
\text { prescriptions } \\
(n=415)\end{array}$} & \multirow[b]{2}{*}{ Analgesic } & \multirow[b]{2}{*}{$\begin{array}{l}\text { No }(\%) \text { of } \\
\text { prescriptions } \\
(n=415)\end{array}$} & \multicolumn{3}{|c|}{$\begin{array}{l}\text { Diagnosis for number }(\%) \text { of } \\
\text { prescriptions }(n=415)\end{array}$} & \multicolumn{3}{|c|}{$\begin{array}{l}\text { Dosage for number }(\%) \\
\text { of prescriptions }(n=415)\end{array}$} \\
\hline & & & & $\begin{array}{l}\text { Compliant } \\
\text { with } \\
\text { STGs/EML }\end{array}$ & $\begin{array}{l}\text { Non- } \\
\text { compliant }\end{array}$ & $\begin{array}{l}\text { No } \\
\text { information }\end{array}$ & $\begin{array}{l}\text { Compliant } \\
\text { with } \\
\text { STGs/EML }\end{array}$ & $\begin{array}{l}\text { Non- } \\
\text { compliant }\end{array}$ & $\begin{array}{l}\text { No } \\
\text { information }\end{array}$ \\
\hline Aniline analgesics & $345(83.1 \%)$ & Paracetamol & $345(83.1 \%)$ & $326(94.5 \%)$ & $11(3.2 \%)$ & $8(2.3 \%)$ & $345(100 \%)$ & - & - \\
\hline \multirow{4}{*}{$\begin{array}{l}\text { Non-steroidal anti- } \\
\text { inflammatory drugs } \\
\text { (NSAIDs) }\end{array}$} & \multirow{4}{*}{$61(14.5 \%)$} & Ibuprofen & $41(9.9 \%)$ & $39(95.1 \%)$ & & $2(4.8 \%)$ & $37(90.2 \%)$ & $4(9.7 \%)$ & - \\
\hline & & Naproxen & $17(4.1 \%)$ & $15(88.2 \%)$ & - & $2(11.7 \%)$ & $16(94.1 \%)$ & $1(5.8 \%)$ & - \\
\hline & & Diclofenac & $2(0.5 \%)$ & $2(100 \%)$ & - & - & $2(100 \%)$ & - & - \\
\hline & & Indomethacin & $1(0.2 \%)$ & $1(100 \%)$ & - & - & $1(100 \%)$ & - & - \\
\hline $\begin{array}{l}\text { Tricyclic anti- } \\
\text { depressants }\end{array}$ & $13.49 \%$ & Amitriptyline & $56(13.5 \%)$ & $54(96.4 \%)$ & $1(0.24 \%)$ & $1(0.24 \%)$ & $56(100 \%)$ & - & - \\
\hline \multirow[t]{2}{*}{ Non-narcotic analgesic } & \multirow[t]{2}{*}{$14(3.3 \%)$} & Carbamazepine & $13(3.1 \%)$ & $13(100 \%)$ & - & - & $13(100 \%)$ & - & - \\
\hline & & Gabapentin & $1(0.24 \%)$ & - & $1(100 \%)$ & - & - & $1(100 \%)$ & - \\
\hline \multirow[t]{2}{*}{ Opioids } & \multirow[t]{2}{*}{$2(0.5 \%)$} & $\begin{array}{l}\text { Codeine } \\
\text { phosphate }\end{array}$ & $1(0.24 \%)$ & - & $1(100 \%)$ & - & - & $1(100 \%)$ & - \\
\hline & & $\begin{array}{l}\text { Morphine } \\
\text { sulphate }\end{array}$ & $1(0.24 \%)$ & $1(100 \%)$ & - & - & $1(100 \%)$ & - & - \\
\hline Anticonvulsants & $1(0.24 \%)$ & Pregabalin & $1(0.24 \%)$ & - & $1(100 \%)$ & - & - & $1(100 \%)$ & - \\
\hline
\end{tabular}

STGs/EML: Standard Treatment Guidelines and Essential Medicines List for South Africa 


\subsection{Compliance of diagnosis, dosage, and the dosage interval of tramadol $\mathrm{HCl}$ with the STGs/EML}

The aspects of compliance such as the diagnosis, dosage, dosage interval have been equally weighted to arrive at a conclusion as to whether the prescription was compliant or not. Tramadol $\mathrm{HCl}$ is the basis of this study; consequently, all aspects of compliance to the guidelines were evaluated.

Compliance was found to be $76.1 \%$ (274) regarding the conditions treated. Non-compliance $(23.9 \% ; 86)$ was due to over prescribing or because some conditions (diagnosis) were not indicated in the STGs/EML. Compliance at the antiretroviral pharmacy was low at $30.9 \%$ because some prescriptions had no direct indication for tramadol $\mathrm{HCl}$ and most had no indication at all (Table 2).

The overall dosage compliance was $99.8 \%$. Only one prescription contained a dose of $200 \mathrm{mg}$ as a single dose. The dosage interval was found to be non-compliant in $95.4 \%$ of prescriptions. The primary reason for non-compliance was that $80.7 \%$ of the prescriptions had a dosage interval of 8hourly whereas the guidelines recommend $4-6$ hourly, which is interpreted as 4-6 times a day (Table 4).

Table 4: Tramadol $\mathrm{HCl}$ dosage and dosage interval compliance with the STGs/EML

\begin{tabular}{|l|l|l|l|}
\hline \multirow{2}{*}{ Dose and dosage interval } & \multicolumn{2}{|l|}{ Compliant with STGs/EML } & \multirow{2}{*}{ No $\%$ of prescriptions } \\
\cline { 2 - 3 } & Dosage & Dosage interval & 20 $\%(72.9 \%)$ \\
\hline $50 \mathrm{mg} 8$ hourly & Yes & No & $68(16.6 \%)$ \\
\hline $50 \mathrm{mg} 12$ hourly & Yes & No & $14(3.4 \%)$ \\
\hline $50 \mathrm{mg} 6$ hourly & Yes & Yes & $13(3.2 \%)$ \\
\hline $100 \mathrm{mg} 8$ hourly & Yes & No & $5(1.3 \%)$ \\
\hline $100 \mathrm{mg} 5$ hourly & Yes & Yes & $4(0.9 \%)$ \\
\hline $100 \mathrm{mg} 12$ hourly & Yes & No & $3(0.7 \%)$ \\
\hline $50 \mathrm{mg}$ when necessary & Yes & No & $3(0.7 \%)$ \\
\hline $50 \mathrm{mg}$ daily & Yes & No & $1(0.24 \%)$ \\
\hline $200 \mathrm{mg}$ daily & No & No & $5(1.2 \%)$ \\
\hline No information & - & - & $\mathbf{4 1 5}(\mathbf{1 0 0} \%)$ \\
\hline $\begin{array}{l}\text { Total number (\%) of } \\
\text { prescriptions }\end{array}$ & $\mathbf{4 1 4}(\mathbf{9 9 . 8 \% )}$ & $\mathbf{1 9}(\mathbf{4 . 6 \% )}$ & \multicolumn{2}{|l|}{} \\
\hline
\end{tabular}

\subsection{Inpatient consumption}

A total of 26100 tramadol HCL tablets were issued to the wards for inpatient use over the period of two months. The breakdown for each ward is shown in Table 5, with more than half (51.5\%) of the total consumption among the surgical wards.

Table 5: Inpatient consumption of tramadol $\mathrm{HCl}$

\begin{tabular}{|l|l|}
\hline Inpatient ward & $\begin{array}{l}\text { Number (\%) of } \\
\text { tablets }\end{array}$ \\
\hline Surgical wards & $13450(51.5 \%)$ \\
\hline Orthopaedic wards & $7400(28.3 \%)$ \\
\hline Medical wards & $3860(14.8 \%)$ \\
\hline Obstetrics and Gynaecology & $1050(4.0 \%)$ \\
\hline Burns ward & $340(1.4 \%)$ \\
\hline Total & $\mathbf{2 6 1 0 0 ( 1 0 0 \% )}$ \\
\hline
\end{tabular}

\subsection{Expenditure on tramadol $\mathrm{HCl}$}

The expense incurred on tramadol $\mathrm{HCl}$ over the 2-month study period by the inpatient pharmacy was \$2, 526.63 (R37 351.20), outpatient pharmacy \$4, 874.13 (R72 054.28) and antiretroviral pharmacy $\$ 590.13$ (R8 722.75). Table 6 presents the hospital expenditure for tramadol HCl per financial year, showing an appreciable increase from 2014-2016 to 2016-2017. 
Table 6: Tramadol $\mathrm{HCl}$ hospital expenditure per financial year

\begin{tabular}{|c|c|c|c|}
\hline \multirow{2}{*}{\multicolumn{2}{|c|}{ Financial year }} & \multicolumn{2}{|c|}{ Expenditure } \\
\hline & & US\$ & ZAR \\
\hline \multicolumn{2}{|l|}{$2014-2015$} & $\$ 10576.04$ & R 156326.00 \\
\hline \multicolumn{2}{|l|}{ 2015-2016 } & $\$ 34258.79$ & R 505602.00 \\
\hline \multicolumn{2}{|l|}{ 2016-2017 } & $\$ 39584.00$ & R 585088.80 \\
\hline \multirow{3}{*}{$\begin{array}{l}\text { Pharmacy } \\
\text { expenditure for } \\
2016-2017\end{array}$} & Outpatient pharmacy (34\%) & $\$ 13571.23$ & R 200288.50 \\
\hline & Inpatient pharmacy (24\%) & $\$ 140519.10$ & R 140519.10 \\
\hline & Antiretroviral pharmacy (5\%) & $\$ 2010.07$ & R 29669.90 \\
\hline
\end{tabular}

\section{Discussion}

Chronic non-cancer pain (32.7\%) followed by acute non-surgical pain $(21.8 \%)$, post-operative pain $(14.8 \%)$ and cancer pain $(5.0 \%)$ were the principal indications for tramadol use in this regional hospital in South Africa. Overall, there was a reasonable level of compliance with the STGs/EML for South Africa, Hospital Level (Adults) and the PHC Level. Compliance to guidelines for the use of tramadol $\mathrm{HCL}$ as per the pain categories was greatest in the outpatient pharmacy at $76.1 \%$ whereas antiretroviral pharmacy compliance was only $30.9 \%$. Overall dosage compliance was $99.8 \%$. All prescriptions reviewed at the antiretroviral pharmacy were written by level 2 medical officers; however, it was noted that most prescriptions had no specific indication for tramadol $\mathrm{HCl}$ and were therefore non-compliant. Consequently, this is an area to address in the future, especially with concerns with tramadol.

Of all the wards, the surgical wards had the highest prescribing of tramadol $\mathrm{HCl}$ tablets at $51.5 \%$ (Table 5) as patients were suffering from cancer, post-operation pain, stab wounds and, in some instances, the wards are treated as a step-down facility for terminally-ill patients who are constantly in pain. This is consistent with the pattern seen when evaluating the OPD clinics.

When assessing the prescriptions from the OPD clinics, it was noted that the SOPD at $33.7 \%$ had the most tramadol $\mathrm{HCl}$ prescriptions, followed by the OOPD at $26.0 \%$. This prescribing pattern may be due to the nature of the conditions of the patients who visit these departments, which ranged from those with cancer, post-operation and chronic pain to post-motor vehicle accident victims. For prescribers at the SOPD, it was often difficult to prescribe anything else apart from paracetamol and tramadol $\mathrm{HCl}$ as most of their patients suffer from epigastric pain or have such related illnesses.

Overall, our findings were encouraging as previous reviews have shown low compliance with STGs/EML for infections and diabetes in Kwa-Zulu-Natal (42-44). However, these reviews did not include the duration of therapy as this was not specified and assumed to be at the discretion of the prescriber assessing the patient.

When evaluating for compliance in adjuvant therapy, the results were found to be consistent with that of tramadol $\mathrm{HCl}$ except for the dosage interval. Paracetamol, amitriptyline, carbamazepine and diclofenac were all $100 \%$ dosage compliant while the diagnosis compliance varied from $94.5 \%$ for paracetamol, $96.4 \%$ for amitriptyline, and up to $100 \%$ for both carbamazepine and diclofenac. Having said this, there needs to be care when tramadol $\mathrm{HCl}$ is co-prescribed with antidepressants and patients with bipolar disorders (14).

There were two situations that could have attributed to and promoted the overuse of tramadol $\mathrm{HCl}$. These are the non-availability of some NSAIDs such as naproxen, and the restriction of others due to their side-effect profiles including indomethacin. In such cases where the first-line agents are not available, prescribers or the pharmacist recommend the next available analgesic in line as it is difficult to send a patient home without medication. This could be tramadol, which will be investigated further in future research projects to help improve the quality of prescribing in this regional hospital. 
As seen, expenditure on tramadol has almost doubled in recent years (Table 6), with the highest expenditure in the OP pharmacy department. We will be looking at this further to see if savings can be made in the future without compromising care. We will also point out to the authorities some of the inconsistencies with for instance PHC STGs/EML recommending tramadol $\mathrm{HCl}$ as a Step 2 weak opioid analgesic but not in the Hospital Level (Adult) STGs/EML $(33,34)$. This can cause problems as seen in Namibia with inconsistencies between national guidelines (45).

We are aware of a number of limitations with this study. It was conducted at only one regional hospital and data was collected over a short period of time which means that the results cannot be generalised. Furthermore, regarding the inpatient wards, only the quantity issued to wards was determined and assessed and no level of medication compliance was investigated in the inpatient setting. However, we believe our findings are robust with concerns identified that need to be addressed in this hospital in addition to further research on the use of tramadol $\mathrm{HCl}$ across public hospitals in South Africa in view of continued concerns with tramadol $\mathrm{HCl}$. Proposed activities also include investigating issues of stock control practices especially if poor stock control leads to higher prescribing of tramadol where there are limited other alternatives. In addition, looking to introduce measures to enhance proper quantification and forecasting of medicine stocks as well as train pharmacy stock controllers in supply chain management, which are all part of recent developments in South Africa (38).

\section{Conclusion and next steps}

Encouragingly, the prescribing of tramadol $\mathrm{HCl}$ was found to be appropriate in most cases in this regional hospital based on the dose, diagnosis and interval indicated in the STGs/EML for South Africa. This is in contrast to other disease areas in this region.

However, a number of areas were identified that need addressing. These include prescribers not writing the diagnosis on the prescription, which is particularly important for medicines such as tramadol, and addressing the fact that some prescriptions had no clear information on them. The latter is particularly important to be able to evaluate prescribing compliance with guidelines. The number of prescriptions written by intern medical offers was also a concern that needs to be addressed. This can potentially be addressed through greater implementation and monitoring pf prescriptions and protocols by the PTC as part of quality improvement practices in the hospital to improve rational prescribing. We are aware of the growing role of PTCs in South Africa as part of government initiatives to improve the use of medicines in hospitals, and such activities can be part of this $(46,47)$.

Concurrent with greater monitoring of prescribing practices and restrictions, there is a need to review why there has been a significant increase in the use of tramadol $\mathrm{HCl}$ in this hospital in recent years with associated increase in expenditure. Addressing these issues with pertinent interventions should help to optimize the use of tramadol $\mathrm{HCl}$ in this and other hospitals in South Africa in line with the recent WHO guidance. Alongside this, the hospital management needs to introduce better systems to restrict and control tramadol $\mathrm{HCl}$ utilization so that patients do not become dependent. Hospital management is also encouraged to introduce drug monitoring and evaluation tools via the PTC to assess prescribing and dispensing patterns on a monthly basis as seen in other settings in South Africa and wider. The findings should be regularly presented to the PTC for implementation to improve drug utilization practices. We will be following up these suggestions in the future and reporting on them.

\section{Funding and conflicts of interest}

The authors declare they have no conflicts of interest although Akhona Fynn works for the Department of Health in KwaZulu-Natal. There was no funding for this research project.

\section{References}

1. Scott LJ, Perry CM. Tramadol: a review of its use in perioperative pain. Drugs. 2000;60(1):139-76.

2. Wiffen PJ, Derry S, Moore RA. Tramadol with or without paracetamol (acetaminophen) for cancer pain. The Cochrane database of systematic reviews. 2017;5:Cd012508. 
3. Duehmke RM, Derry S, Wiffen PJ, Bell RF, Aldington D, Moore RA. Tramadol for neuropathic pain in adults. The Cochrane database of systematic reviews. 2017;6:Cd003726.

4. Bravo L, Mico JA, Berrocoso E. Discovery and development of tramadol for the treatment of pain. Expert opinion on drug discovery. 2017;12(12):1281-91.

5. Chen S, Argáez C. Tramadol for the Management of Pain in Adult Patients: A Review of Clinical Effectiveness - An Update. Canadian Agency for Drugs and Technologies in Health.

2018. Available from: https://www.ncbi.nlm.nih.gov/books/NBK538277/.

6. Hallam C. Tramadol: Three cheers for the Expert Committee on Drug Dependence. 2019. Available at URL: https://idpc.net/blog/2019/02/tramadol-three-cheers-for-the-expert-committee-ondrug-dependence.

7. Lara-Solares A, Ahumada Olea M, Basantes Pinos A, et al. Latin-American guidelines for cancer pain management. Pain Manag. 2017;7:287-298.

8. WHO. Expert Committee on Drug Dependence, forty first meeting. Critical review report: tramadol, 12-16 November 2018. Available at URL:

https://pdfs.semanticscholar.org/7dc1/e1ed6ed7ff24ffc1a2277c997a3a2f1c88dd.pdf?_ga=2.20706 7347.157605658.1579733338-818319244.1579733338.

9. $\quad$ Yorke E, Oyebola FO, Otene SA, Klein A. Tramadol: a valuable treatment for pain in Ghana and Nigeria. CURRENT MEDICAL RESEARCH AND OPINION. 2019; 35 (5): 777-784.

10. Brinker A, Bonnel RA, Beitz J. Abuse, dependence, or withdrawal associated with tramadol. The American journal of psychiatry. 2002;159(5):881

11. Sansone RA, Sansone LA. Tramadol: seizures, serotonin syndrome, and coadministered antidepressants. Psychiatry. 2009;6(4):17-21.

12. Jean YK, Gitlin MC, Reynolds J, Candiotti KA. Tramadol-associated hallucinations: a systematic review and narrative synthesis of their pathophysiology, diagnosis, and treatment. Canadian journal of anaesthesia. 2019.

13. Nakhaee S, Amirabadizadeh A, Brent J, Miri-Moghaddam E, Foadoddini M, Farrokhfall K et al. Tramadol and the occurrence of seizures: a systematic review and meta-analysis. Critical reviews in toxicology. 2020:1-14.

14. Subedi M, Bajaj S, Kumar MS, Yc M. An overview of tramadol and its usage in pain management and future perspective. Biomedicine \& Pharmacotherapy. 2019;111:443-51.

15. Ryan NM, Isbister GK. Tramadol overdose causes seizures and respiratory depression but serotonin toxicity appears unlikely. Clinical toxicology. 2015;53(6):545-50.

16. Rahimi HR, Soltaninejad K, Shadnia S. Acute tramadol poisoning and its clinical and laboratory findings. Journal of research in medical sciences. 2014;19(9):855-9.

17. Habibollahi P, Garjani A, Shams Vahdati S, Sadat-Ebrahimi SR, Parnianfard N. Severe complications of tramadol overdose in Iran. Epidemiology and health. 2019;41:e2019026.

18. Kostev K, Von Vultee C, Usinger DM, Reese JP. Tramadol prescription patterns in patients followed by general practitioners and orthopedists in Germany in the year 2015. Postgraduate medicine. 2018;130(1):37-41.

19. Miotto K, Cho AK, Khalil MA, Blanco K, Sasaki JD, Rawson R. Trends in Tramadol: Pharmacology, Metabolism, and Misuse. Anesthesia and analgesia. 2017;124(1):44-51.

20. WHO. Expert Committee on Drug Dependence, Tramadol: Pre-Review Report Agenda item 5.3. 2017. Available at URL: http://www.who.int/medicines/access/controlledsubstances/PreReview_Tramadol.pdf?ua=1.

21. WHO. WHO Expert Committee on Drug Dependence, forty first report. 2019. Available at URL: https://apps.who.int/iris/bitstream/handle/10665/325073/9789241210270-eng.pdf?ua=1.

22. Martinez V, Guichard L, Fletcher D. Effect of combining tramadol and morphine in adult surgical patients: a systematic review and meta-analysis of randomized trials. British journal of anaesthesia. 2015;114(3):384-95.

23. Thiels CA, Habermann EB, Hooten WM, Jeffery MM. Chronic use of tramadol after acute pain episode: cohort study. BMJ. 2019;365:I1849.

24. Chaparro LE, Furlan AD, Deshpande A, Mailis-Gagnon A, Atlas S, Turk DC. Opioids compared with placebo or other treatments for chronic low back pain: an update of the Cochrane Review. Spine. 2014;39(7):556-63.

25. Cepeda MS, Camargo F, Zea C, Valencia L. Tramadol for osteoarthritis: a systematic review and metaanalysis. The Journal of rheumatology. 2007;34(3):543-55.

26. Cepeda MS, Camargo F, Zea C, Valencia L. Tramadol for osteoarthritis. The Cochrane database of systematic reviews. 2006(3):Cd005522.

27. Whittle SL, Richards BL, Husni E, Buchbinder R. Opioid therapy for treating rheumatoid arthritis pain. The Cochrane database of systematic reviews. 2011(11):Cd003113. 
28. National Institute of Health - LiverTox. Drug Record - Tramadol. 2019. Available at URL: https://livertox.nlm.nih.gov/Tramadol.htm.

29. Blanch B, Pearson SA, Haber PS. An overview of the patterns of prescription opioid use, costs and related harms in Australia. British journal of clinical pharmacology. 2014;78(5):1159-66. 30. We Do Recover. Tramadol addiction. 2019. Available at URL:

https://wedorecover.com/addiction/addiction-types/tramadol-addiction/.

31. WHO. WHO GUIDELINES FOR THE PHARMACOLOGICAL AND RADIOTHERAPEUTIC MANAGEMENT OF CANCER PAIN IN ADULTS AND ADOLESCENTS. 2018. Available at URL: file://C:/Users/mail/Downloads/9789241550390-eng.pdf.

32. Republic of South Africa. Essential Drugs Programme. EML Clinical Guide Mobile Application. Republic of South Africa: National Department of Health. 2014. Available at URL: http://www.health.gov.za/index.php/affordable-medicines/category/522-eml-clinical-guidelineapplication

33. Republic of South Africa. Essential Drugs Programme. Primary Healthcare Standard Treatment Guideline and Essential Medicine List. 6th ed. National Department of Health; 2018. Available at URL: file:///C:/Users/mail/Downloads/primaryhealthcarelevel_2018_signed\%20(1).pdf. 34. Republic of South Africa. Essential Drugs Programme. Hospital level (Adults) Standard Treatment Guidelines and Essential Medicines List. 4th ed. Republic of South Africa: National Department of Health. 2015. Available at URL: http://www.kznhealth.gov.za/pharmacy/hospitallevel_adult2015.pdf.

35. Academy of Managed Care Pharmacy. Drug Utilization Review. 2019. Available at URL: https://www.amcp.org/about/managed-care-pharmacy-101/concepts-managed-carepharmacy/drug-utilization-review.

36. Carver N, Dering Anderson AM. Drug Utilization Review (DUR). StatPearls. Treasure Island (FL): StatPearls Publishing. StatPearls Publishing LLC.; 2019.

37. Sacristan JA, Soto J. Drug utilisation studies as tools in health economics. PharmacoEconomics. 1994;5(4):299-312.

38. Meyer JC, Schellack N, Stokes J, Lancaster R, Zeeman H, Defty D, et al. Ongoing Initiatives to Improve the Quality and Efficiency of Medicine Use within the Public Healthcare System in South Africa; A Preliminary Study. Frontiers in pharmacology. 2017;8:751.

39. Nakwatumbah S, Kibuule D, Godman B, Haakuria V, Kalemeera F, Baker A, et al. Compliance to guidelines for the prescribing of antibiotics in acute infections at Namibia's national referral hospital: a pilot study and the implications. Expert review of anti-infective therapy. 2017;15(7):713-21.

40. Niaz Q, Godman B, Massele A, Campbell S, Kurdi A, Kagoya HR, et al. Validity of World Health Organisation prescribing indicators in Namibia's primary healthcare: findings and implications. International journal for quality in health care. 2019;31(5):338-45.

41. KZN Department of Health, South Africa. KZN Health Intranet Pharmaceutical Services. 2015.

42. Hlongwana S, Bezuidenhout S, Helberg E. Adherence to the Primary Health Care Standard Treatment Guidelines in a pediatric sample with respiratory conditions in Umkhanyakude Health District, KwaZulu Natal, South Africa. AJPHERD, 2015; 21 (S 2:2): 330-342.

43. Rampersad K, Rangiah S, Kendon M. Compliance with local diabetic guidelines at a district hospital in KwaZulu-Natal, South Africa. South African Family Practice 2019; 61(2): 60-64. 44. Igbojiaku OJ, Harbor OC, Ross A. Compliance with diabetes guidelines at a regional hospital in KwaZulu-Natal, South Africa. African Journal of Primary Health Care \& Family Medicine. 2013;5(1):447.

45. Kibuule D, Mubita M, Naikaku E, Kalemeera F, Godman BB, Sagwa E. An analysis of policies for cotrimoxazole, amoxicillin and azithromycin use in Namibia's public sector: Findings and therapeutic implications. International journal of clinical practice. 2017;71(2).

46. Matlala M, Gous AG, Godman B, Meyer JC. Structure and activities of pharmacy and therapeutics committees among public hospitals in South Africa; findings and implications. Expert review of clinical pharmacology. 2017;10(11):1273-80.

47. Mashaba TP, Matlala M, Godman B, Meyer JC. Implementation and monitoring of decisions by pharmacy and therapeutics committees in South African public sector hospitals. Expert review of clinical pharmacology. 2019;12(2):159-68. 


\section{Supplementary data}

Supplement A: Compliance of diagnosis per pain classification category as per STGs/EML $(n=360)$

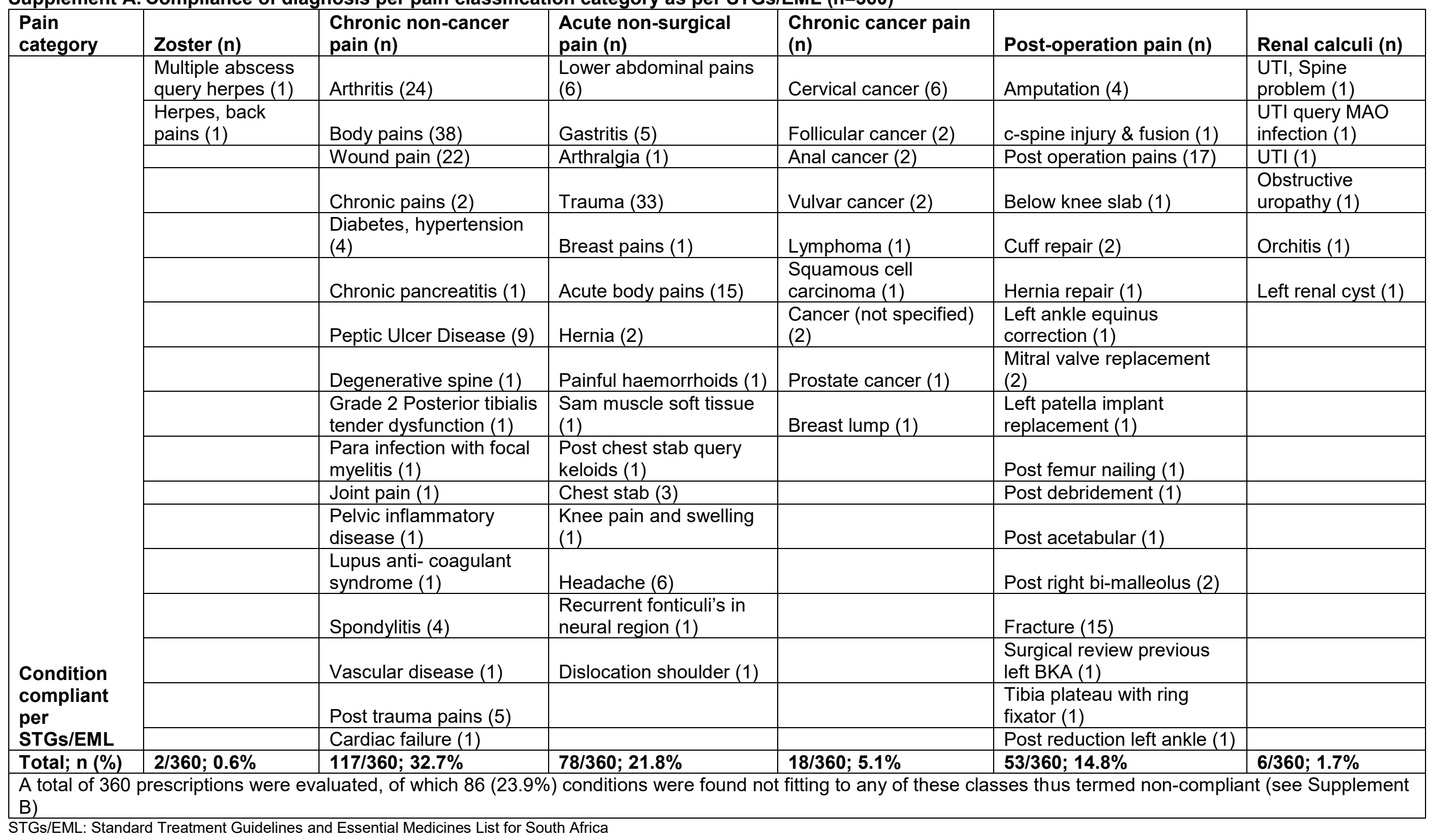


Supplement B:Conditions for which tramadol HCL was prescribed, not in compliance with STGs/EML

\begin{tabular}{|c|c|c|}
\hline Condition & Frequency & Reasons no indication \\
\hline Warts & 6 & Not indicated in the standard treatment guidelines \\
\hline Haemorrhoids & 5 & Not indicated in the standard treatment guidelines \\
\hline Deep vein thrombosis & 4 & Not indicated in the standard treatment guidelines \\
\hline Tuberculosis & 3 & Not indicated in the standard treatment guidelines \\
\hline Recurrent tonsillitis & 3 & $\begin{array}{l}\text { Not indicated in the standard treatment guidelines, } \\
\text { paracetamol can be used for pain and fever }\end{array}$ \\
\hline Abscess & 3 & Not indicated in the standard treatment guidelines \\
\hline Mass in the abdomen & 2 & $\begin{array}{l}\text { Not indicated in the standard treatment guidelines, } \\
\text { often caused by constipation and over use }\end{array}$ \\
\hline Brain tumour & 2 & Contraindicated as it involves a brain injury \\
\hline Epilepsy & 2 & $\begin{array}{l}\text { Not recommended in the standard treatment } \\
\text { guidelines }\end{array}$ \\
\hline Lipoma & 2 & $\begin{array}{l}\text { Condition often regarded as painless and tramadol is } \\
\text { not indicated in the guidelines }\end{array}$ \\
\hline Mass in the abdomen & 2 & $\begin{array}{l}\text { Not indicated in the standard treatment guidelines, } \\
\text { often caused by constipation and over use }\end{array}$ \\
\hline Toe and leg cellulitis & 2 & $\begin{array}{l}\text { Not indicated in the standard treatment guidelines } \\
\text { and over use of tramadol }\end{array}$ \\
\hline Hypothyroidism & 2 & Only thyroxine is indicated in the guidelines \\
\hline Blurred vision & 1 & $\begin{array}{l}\text { Not indicated in the standard treatment guidelines } \\
\text { and condition not usually painful }\end{array}$ \\
\hline Odynophagia & 1 & Treatment depends on the underlying condition \\
\hline Nipple discharge & 1 & Not indicated in the standard treatment guidelines \\
\hline Sinusitis & 1 & Not indicated in the standard treatment guidelines \\
\hline Hypertension & 1 & Not indicated in the standard treatment guidelines \\
\hline Abnormal bleeding & 1 & Not indicated in the standard treatment guidelines \\
\hline $\begin{array}{l}\text { Hypertension and chronic obstructive } \\
\text { pulmonary disease }\end{array}$ & 1 & $\begin{array}{l}\text { Not indicated in the standard treatment guidelines } \\
\text { and tramadol causes respiratory depression }\end{array}$ \\
\hline Ingrown rib & 1 & Not indicated in the standard treatment guidelines \\
\hline Peri-anal mass & 1 & Not indicated in the standard treatment guidelines \\
\hline Retained placenta & 1 & Not indicated in the standard treatment guidelines \\
\hline Swelling and laceration on the head & 1 & Contraindicated as it involves a brain injury \\
\hline Motor Vehicle Accident & 1 & Not a condition but an incident \\
\hline $\begin{array}{lccc}\text { Chronic serous otitis } & \text { media } \\
\text { (CSOM)and asthma } & & \\
\end{array}$ & 1 & $\begin{array}{l}\text { Not indicated in the standard treatment guidelines } \\
\text { and tramadol causes respiratory depression }\end{array}$ \\
\hline Bleeding oesophagus & 1 & Not indicated in the standard treatment guidelines \\
\hline Hepatitis associated antigen & 1 & Not a condition therefore not indicated \\
\hline Hyperthyroidism & 1 & Not indicated in the standard treatment guidelines \\
\hline Cyst on the face & 1 & Not indicated in the standard treatment guidelines \\
\hline Dry cough & 1 & $\begin{array}{l}\text { Not indicated in the standard treatment guidelines } \\
\text { and over use }\end{array}$ \\
\hline $\begin{array}{l}\text { Valgus deformity and leg length } \\
\text { discrepancy }\end{array}$ & 1 & $\begin{array}{l}\text { Not indicated in the standard treatment guidelines } \\
\text { and over use of tramadol }\end{array}$ \\
\hline Chronic atrial fibrillation & 1 & Not indicated in the standard treatment guidelines \\
\hline Lip laceration & 1 & $\begin{array}{l}\text { Not indicated in the standard treatment guidelines, } \\
\text { over use of tramadol }\end{array}$ \\
\hline Psoriasis & 1 & $\begin{array}{l}\text { Not indicated in the standard treatment guidelines, } \\
\text { over use of tramadol }\end{array}$ \\
\hline Cholecystitis & 1 & $\begin{array}{l}\text { Not indicated in the standard treatment guidelines, } \\
\text { over use of tramadol }\end{array}$ \\
\hline Fibroadenoma & 1 & $\begin{array}{l}\text { Not indicated in the standard treatment guidelines, } \\
\text { over use of tramadol }\end{array}$ \\
\hline Sebaceous cyst & 1 & $\begin{array}{l}\text { Not indicated in the standard treatment guidelines, } \\
\text { over use of tramadol }\end{array}$ \\
\hline Critical care medicine & 1 & Not indicated in the standard treatment guidelines \\
\hline Sub-total & 64 & \\
\hline Condition not clear & 13 & \\
\hline No diagnosis/ indication specified & 8 & \\
\hline Total & 86 & \\
\hline
\end{tabular}

STGs/EML: Standard Treatment Guidelines and Essential Medicines List for South Africa 
Supplement C: Recommendations on the suggested treatment approaches as stipulated by the STGs/EML

\begin{tabular}{|c|c|c|c|}
\hline Class & Analgesic & $\begin{array}{l}\text { Dose and dosage } \\
\text { interval }\end{array}$ & Maximum dose \\
\hline \multicolumn{4}{|c|}{ Analgesic for chronic non-cancer pain } \\
\hline \multirow[t]{2}{*}{ Mild/ moderate pain } & Paracetamol & 1g 4-6 hourly & 4 doses in 24 hours, $15 \mathrm{mg} / \mathrm{kg} / \mathrm{dose}, 4 \mathrm{~g}$ in 24 hours \\
\hline & Ibuprofen & 400mg 8 hourly & $\begin{array}{l}2400 \mathrm{mg} \text { per day, nurses prescribe a max of } \\
1200 \mathrm{mg}\end{array}$ \\
\hline \multirow[t]{3}{*}{ Severe pain } & Tramadol (combined treatment is suggested) & $50-100 \mathrm{mg} 6$ hourly & 400mg per day \\
\hline & Add morphine syrup & 10-15mg 4 hourly & $0.2 \mathrm{mg} / \mathrm{kg} 4$ hourly \\
\hline & $\begin{array}{l}\text { Change to morphine long acting oral once } \\
\text { stable }\end{array}$ & $10 \& 30 \mathrm{mg} 12$ hourly & $60 \mathrm{mg} 12$ hourly \\
\hline \multicolumn{4}{|l|}{$\begin{array}{l}\text { Chronic cancer pain } \\
\text { This follows the same a }\end{array}$} \\
\hline \multirow[t]{2}{*}{ Chronic neuropathic pain } & Amitriptyline & $10 \mathrm{mg}$ at night & $75 \mathrm{mg}$ at night \\
\hline & $\begin{array}{l}\text { If not well managed add or replace with } \\
\text { Carbamazepine (refer if unresponsive) }\end{array}$ & 100-200mg 12 hourly & 600mg 12 hourly \\
\hline \multicolumn{4}{|c|}{$\begin{array}{l}\text { Acute non-surgical pain } \\
\text { Analgesic treatment is that of acute postoperative pain, that is postoperative pain in the recovery room. Those already on opioids for chronic pain must be monitored } \\
\text { for respiratory and cardiovascular depression. }\end{array}$} \\
\hline \multirow[t]{3}{*}{ Zoster } & Paracetamol & 1g 4-6 hourly & 4 doses in 24 hours, $15 \mathrm{mg} / \mathrm{kg} / \mathrm{dose}, 4 \mathrm{~g}$ in 24 hours \\
\hline & Tramadol & $50-100 \mathrm{mg} 6$ hourly & 400mg per day \\
\hline & Amitriptyline & $25 \mathrm{mg}$ at night & $75 \mathrm{mg}$ at night \\
\hline \multirow[t]{3}{*}{ Perioperative analgesics } & Paracetamol & 1g 4-6 hourly & 4 doses in 24 hours, $15 \mathrm{mg} / \mathrm{kg} / \mathrm{dose}, 4 \mathrm{~g}$ in 24 hours \\
\hline & Add Tramadol & $50-100 \mathrm{mg} 6$ hourly & 400mg per day \\
\hline & Add NSAID e.g. ibuprofen & 400mg 8 hourly & 2400mg a day \\
\hline \multicolumn{4}{|l|}{ Postoperative pain } \\
\hline \multicolumn{4}{|c|}{ Post-operative analgesia in the recovery room } \\
\hline \multirow[t]{2}{*}{ Mild pain } & Paracetamol & 1g 4-6 hourly & 4 doses in 24 hours, $15 \mathrm{mg} / \mathrm{kg} / \mathrm{dose}, 4 \mathrm{~g}$ in 24 hours \\
\hline & NSAID e.g. Ibuprofen & 400mg 8 hourly & $\begin{array}{l}2400 \mathrm{mg} \text { per day, nurses prescribe a max of } \\
1200 \mathrm{mg}\end{array}$ \\
\hline \multirow[t]{3}{*}{ Moderate pain } & Tramadol & 50-100mg 6 hourly & 400mg per day \\
\hline & Paracetamol & 1g 4-6 hourly & 4 doses in 24 hours, $15 \mathrm{mg} / \mathrm{kg} / \mathrm{dose}, 4 \mathrm{~g}$ in 24 hours \\
\hline & NSAID e.g. Ibuprofen & 400mg 8 hourly & $\begin{array}{l}2400 \mathrm{mg} \text { per day, nurses prescribe a max of } \\
1200 \mathrm{mg}\end{array}$ \\
\hline \multirow[t]{2}{*}{ Severe pain } & Tramadol & 50-100mg 6 hourly & 400mg per day \\
\hline & Morphine & IM $0.1-0.2 \mathrm{mg} / \mathrm{kg} 4$ hourly & $0.1-0.2 \mathrm{mg} / \mathrm{kg} 4$ hourly \\
\hline
\end{tabular}




\begin{tabular}{|c|c|c|c|}
\hline Class & Analgesic & $\begin{array}{l}\text { Dose and dosage } \\
\text { interval }\end{array}$ & Maximum dose \\
\hline & Morphine & $\begin{array}{l}1 \mathrm{mg} \text { bolus every } 6-10 \\
\text { minutes }\end{array}$ & \\
\hline \multirow[t]{4}{*}{ Opiate withdrawal } & Diazepam & $\begin{array}{l}\text { 5-20 mg / day in divided } \\
\text { doses }\end{array}$ & \\
\hline & Paracetamol & 1g 4-6 hourly & 4 doses in 24 hours, $15 \mathrm{mg} / \mathrm{kg} / \mathrm{dose}, 4 \mathrm{~g}$ in 24 hours \\
\hline & NSAID e.g. Ibuprofen & 400mg 8 hourly & $\begin{array}{l}2400 \mathrm{mg} \text { per day, nurses prescribe a max of } \\
1200 \mathrm{mg}\end{array}$ \\
\hline & $\begin{array}{l}\text { Methadone (in case of unavailability tramadol } \\
200 \mathrm{mg} 12 \text { hourly for } 2 \text { weeks) }\end{array}$ & 5-10mg 2-4 hourly & $30 \mathrm{mg}$ per 24 hours \\
\hline \multicolumn{4}{|l|}{ Pain control } \\
\hline $\begin{array}{l}\text { Mild pain; non-opioid treatment, } \\
\text { non-inflammatory pain }\end{array}$ & Paracetamol & $\begin{array}{l}10-15 \mathrm{mg} / \mathrm{kg} / \mathrm{dose} \text { for } \\
\text { children } \\
1 \mathrm{~g} 6 \text { hourly when required }\end{array}$ & $4 g$ per day \\
\hline $\begin{array}{l}\text { Associated with trauma or } \\
\text { inflammation }\end{array}$ & NSAIDS e.g. Ibuprofen & $400 \mathrm{mg} 6-8$ hourly & $\begin{array}{l}2400 \mathrm{mg} \text { per day and nurses may only prescribe } \\
1200 \mathrm{mg}\end{array}$ \\
\hline $\begin{array}{l}\text { Moderate - if no relief to } \\
\text { paracetamol }\end{array}$ & $\begin{array}{l}\text { NSAIDS e.g. Ibuprofen if no relief, add } \\
\text { tramadol }\end{array}$ & 50mg 4-6 hourly & $400 \mathrm{mg}$ daily \\
\hline Severe pain & $\begin{array}{l}\text { Tramadol } \\
\text { Add paracetamol } \\
\text { Or morphine IM 10-15mg }\end{array}$ & $\begin{array}{l}50 \mathrm{mg} 4-6 \text { hourly } \\
1 \mathrm{~g} 6 \text { hourly when } \\
\text { IM } 10-15 \mathrm{mg} 4-5 \text { hourly }\end{array}$ & $\begin{array}{l}400 m g \text { daily } \\
4 g \text { per day }\end{array}$ \\
\hline \multicolumn{4}{|l|}{ Cancer pain } \\
\hline Step 1a & Paracetamol & 1g 6 hourly & $4 \mathrm{~g}$ per day \\
\hline Step 1b & NSAIDS e.g. Ibuprofen & 400mg 6-8 hourly & $\begin{array}{l}2400 \mathrm{mg} \text { per day and nurses may only prescribe } \\
1200 \mathrm{mg}\end{array}$ \\
\hline Step 2 & Tramadol & 50mg 4-6 hourly & 400mg daily \\
\hline Step 3 & $\begin{array}{l}\text { To Paracetamol and or . Ibuprofen add } \\
\text { morphine }\end{array}$ & 5-10mg 4 hourly & No maximum dose - dose is titrated upwards \\
\hline
\end{tabular}

STGs/EML: Standard Treatment Guidelines and Essential Medicines List for South Africa 
